\title{
AN UNUSUAL FOREIGN BODY IN THE BRONCHUS
}

\author{
Surg Cdr PS TAMPI ${ }^{*}$, Surg Cdr S GANESAN ${ }^{+}$, \\ Surg Lt Cdr D RAGHAVAN ${ }^{*}$, Col HS PRUTHI ${ }^{* *}$, \\ Col BN BORGOHAIN ${ }^{++}$
}

\author{
MJAFI 2001; $57: 161-162$
}

KEY WORDS :Bronchial foreign body; Fïre optic bronchoscopy; Fluoroscopy

\section{Introduction}

$\mathbf{F}$ oreign body aspiration can be the cause of both upper and lower airway obstruction and can occur both in adults and children. Children are likely to aspirate toys, coins and hard candy; while adults more commonly aspirate food particles like meat bones and dental appliances. Inhaled or aspirated foreign bodies are known to cause acute upper airway obstruction, laryngeal edema, central obstructive collapse and obstructive emphysem. If the obstruction is severe and acute it can even lead to sudden death, sub acute and chronic complications including post obstructive pneumonia, lung abscess formation, bronchiectasis and foreign body granuloma. Immediate removal of foreign body and prompt resuscitation can often be life saving [1]. One of the earliest uses of bronchoscope was for removal of aspirated foreign bodies. In the present day, both rigid and fibreoptic bronchoscopes have been widely used for this purpose. The ingenuity of the bronchoscopists has resulted in the invention of various modified devices to remove foreign bodies from the tracheobronchial tree [2]. We report one such case of an unusual foreign body in a distal bronchus that was retrieved successfully.

\section{Case Report}

A 21 year old medical assistant was on duty in the casuilty. He was involved mainly in making admission papers of patients. While making the admission filmsy of a patient, he had kept a paper pin between his teeth. He opened his mouth to say something when the paper pin accidentaly slipped into, and beyond his oral cavity. He immediately had a bout of coughing which persisted for some time, after which, the cough subsided spontaneously. But the paper pin could not be located. The pin had neither been coughed out, nor could it be seen within the oro-naso-pharynx. He did not have any foreign body sensation or pain in his throat while coughing/swallowing, hemoptysis, chest pain or respiratory difficulty.
An immediate detailed ENT examination including an indirect laryngoscopy was normal with no sign of the missing pin or any injury to the upper airway or the esophagus. Clinical examination of the Gastrointestinal System and Respiratory System was essentially normal. There was no stridor.

A chest radiograph revealed the pin to be lying head-down just behind the heart and could be seen to pulsate with every heart beat on fluoroscopy (Fig-1). He was then subjected to plain CT scan of the chest. The paper pin was located in the sub-segments of the anterior basal segment bronchus of left lower lobe. The patient was then taken up for fibreoptic bronchoscopy in the operating room under local anaesthesia and conscious sedation. Despite all efforts and a thorough search, the pin could not be visualized through the scope. It was felt that the pin was possibly lying distal to the farthest point that could be traversed by the fibreoptic bron choscope in the bronchial tree.

It was then decided to repeat the procedure, but this time under fluoroscopic guidance in the Radiology Department. Under fluoroscopic guidance, the paper pin was confirmed to be iying head-down about five centimeters beyond the tip of fibre optic bronchoscope, but was still not visisble through the bronchoscope. Initially a guide-wire was passed through the working channel and extruded out of the distal end of the scope. An attempt to manoeu vre the scope over the guide-wire into the sub-segmental bronchus containing the pin was unsuccessful. The guide-wire was withdrawn and an alligator biopsy forceps was introduced through the working channel. Under fluoroscopic guidance, the alligator biopsy forceps was extended beyond the tip of the scope and with some difficulty and manocuvring, it was guided into the desired sub-segmental bronchus. The open forceps was then gently advanced and the pin was firmly grasped between its blades (Fig-2). Thereafter the bronchoscope and the alligator forceps holding the pin were gently withdrawn together the entire procedure being visualized on the fluoroscopy screen. The pin was successfully retrieved from the patient.

A repeat tibreoptic bronchoscopy excluded any local injury or hemorrhuge in the affected segment and the remaining upper and lower tracheo-bronchial tree. There were no complications from the procedure. The patient was conscious, cooperative throughout and withstood the procedure well.

\section{Discussion}

About two thirds of foreign bodies lodge in the main stem bronchus and the remainder are found in

"Classified Specialist (Medicine \& Pulmonology), ${ }^{+}$Classified Specialist (Radiodiagnosis), "Graded Specialist (Otolaryngology), "Senior Adviser \& Head, Department of Medicine, ${ }^{++}$Senior Adviser \& Head, Department of Otolaryngology, INHS Asvini, Colaba, Mumbai 400005 . 


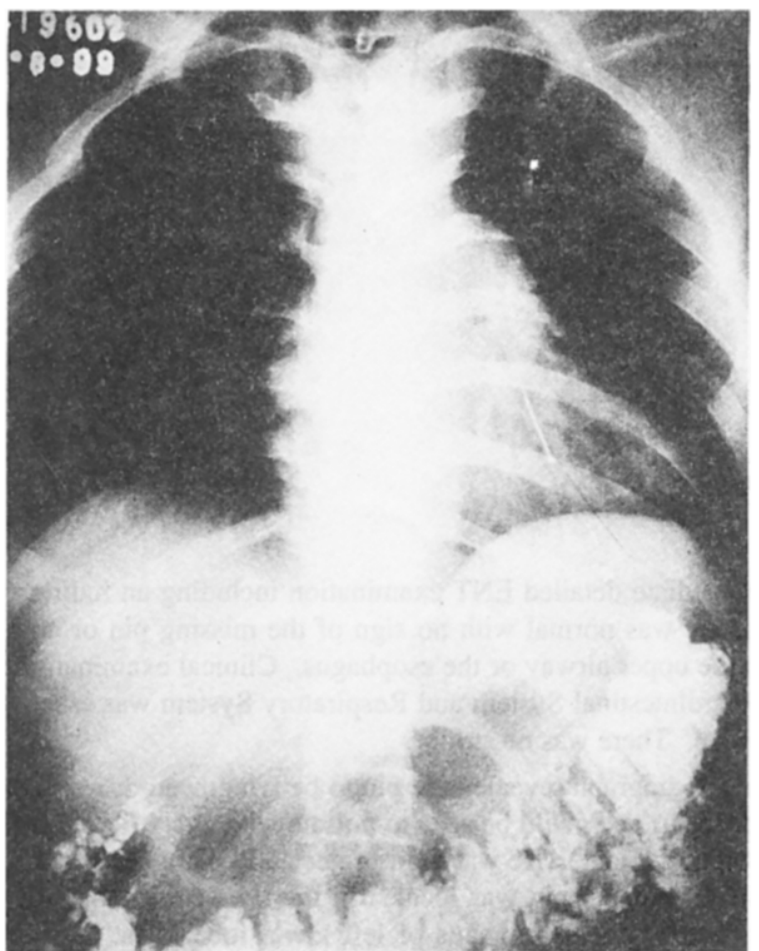

Fig. 1: Chest $\mathrm{X}$-ray (PA) view showing foreign body in lower sub-segmental bronchus

the lobar bronchi. They cause obstructive emphysema about five times as often as obstructive collapse [1]. The Cafe Coronary Syndrome is the name given to the sudden aspiration of a bolus of food, usually meat, into the hypopharynx and upper portion of the larynx [2]. This can result in sudden respiratory embarassment while eating and the victim is suddenly unable to talk or breathe. Here, the Hcimlich manocuvre may be lifesaving. Risk factors for foreign body aspiration include advanced age, altered state of consciousness due to alcohol or drugs, poor dentition and neurological disorders such as Parkinson's disease and stroke [3].

Until the introduction of fibreoptic bronchoscope, all procedures were done through the rigid bronchoscope. The latter, being of a large caliber and rigid has its obvious limitations when exploring the distal bronchial tree. Various types of grasping forceps, retrieval baskets and magnetic devices have been developed in order to remove foreign bodies of all kinds from the tracheo-bronchial tree [4].

Special attention should be paid to the period after removal of foreign body- a time when complications can occur. Paients should be observed for any signs of hemoptysis or subglottic edema [5].

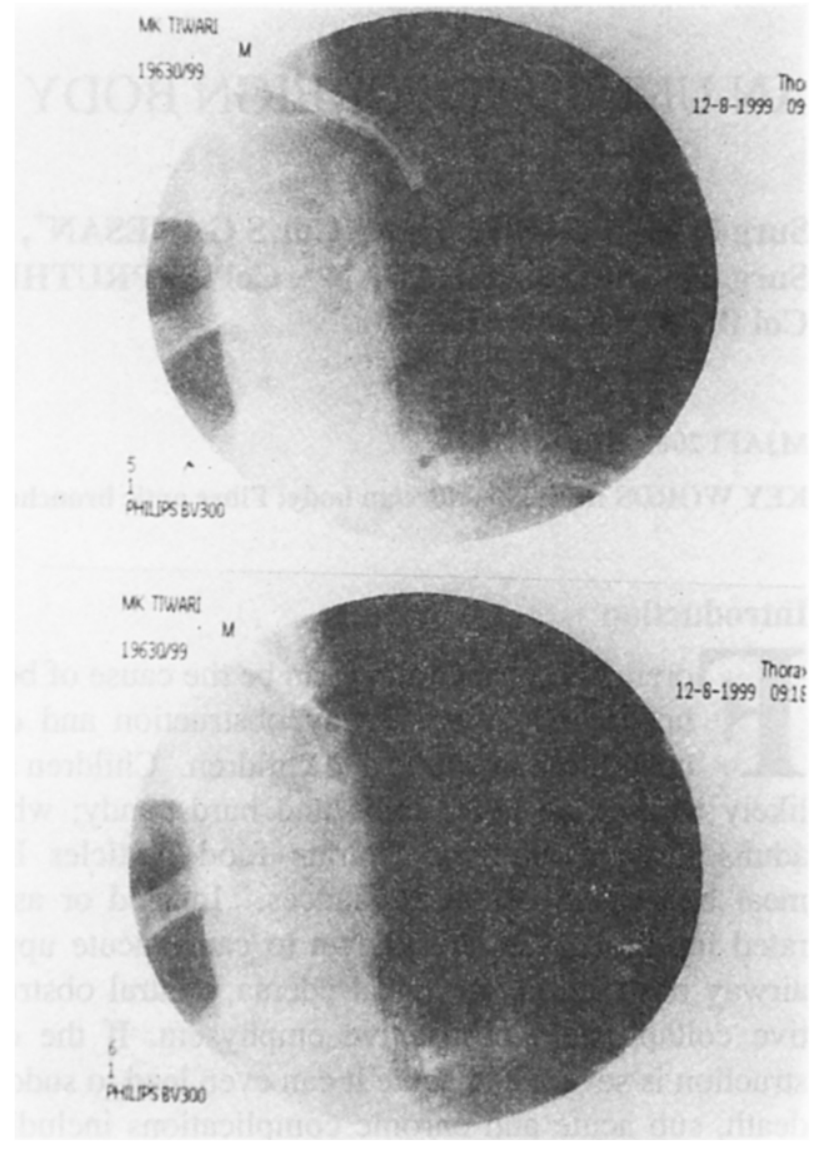

Fig. 2: Pin firmly grasped with alligator forceps and withdrawn along with bronchoscope

In the case cited, we have successfully removed a foreign body (paper pin) in left lower lobe sub-segmental bronchus under fluoroscopic guidance using a minimally invasive fibreoptic bronchosope and an alligattor forceps, thereby obviating surgical thoracotomy.

\section{References}

1. Kryger M. Bode F, Antic R. Anthonisen N. Diannossis of obitruction of the upper and central airways, Am J Med 1976; 61(1):8.5-93.

2. Jackson C. Jackson CL. Bronchoscopy, in Bronchoesophagology. Philadelphia. WB Sauders 1950:50-67.

3. Tietjen PA, Kaner RJ, Quinn C.E. Aspiration emergencies. Clin Chest Med 1994:15(1)117-35.

4. Heimlich HJ. A life-saving manoeuvre to prevent food choking. JAMA 1975:234(4):398-401.

5. Kim IG, Brummitt WM. Humphry A, Siomara SW, Wallace WB. Foreign body in the airway : a review of 202 cases. Laryngoscope 1973;83(3):34;-54.

6. Unger M, Sterman D. Bronchoscopy. Transthoracic Needle Respiration and Related Procedures, in Fishman's Pulmonary Diseases and Disorders, 3rd ed. Philadelphia, Mc Graw Hill. 1998:589-606. 